\title{
Dietary Soy Protein Isolate and Its Undigested High Molecular Fraction Upregulate Hepatic ATP-Binding Cassette Transporter G5 and ATP-Binding Cassette Transporter G8 mRNA and Increase Biliary Secretion of Cholesterol in Rats
}

\author{
Ikuo IKEDA $^{1}$, Mariko KudO ${ }^{2}$, Tadateru HAMADA ${ }^{2}$, Koji NAGAO $^{3}$, Yoko OSHIRO ${ }^{1}$, Masaki KATO ${ }^{1}$, \\ Takashi SugaWArA ${ }^{1}$, Takashi YamahirA ${ }^{1}$, Hiroko Ito ${ }^{1}$, Shogo TAMArU ${ }^{1}$, Masao SATO ${ }^{2}$, \\ Katsumi ImAIzumi ${ }^{2}$, Satoshi NAGAOKA ${ }^{4}$ and Teruyoshi YANAGITA ${ }^{3}$ \\ ${ }^{1}$ Laboratory of Food and Biomolecular Science, Graduate School of Agricultural Science, \\ Tohoku University, Sendai, Miyagi 981-8555, Japan \\ ${ }^{2}$ Laboratory of Nutrition Chemistry, Faculty of Agriculture, Graduate School of Kyushu University, \\ Fukuoka 812-8581, Japan \\ ${ }^{3}$ Laboratory of Nutrition Biochemistry, Faculty of Agriculture, Saga University, Saga 840-8502, Japan \\ ${ }^{4}$ Laboratory of Molecular Function of Food, Faculty of Applied Biological Sciences, Gifu University, \\ Gifu 501-1193, Japan
}

(Received November 13, 2008)

\begin{abstract}
Summary Dietary soy protein isolate (SPI) and its undigested high molecular fraction (HMF) exhaustively digested with proteases, compared with casein (CAS), significantly reduced serum and liver cholesterol concentration in rats. Biliary excretion of cholesterol was significantly higher in rats fed SPI and HMF than in those fed CAS. Hepatic expression of ATP-binding cassette transporter G5 (ABCG5) and ATP-binding cassette transporter G8 (ABCG8) mRNA was significantly higher in rats fed SPI and HMF than in those fed CAS. These observations suggest that increased biliary excretion of cholesterol in SPI and HMF groups is caused by the enhanced expression of $\mathrm{Abcg} 5 / \mathrm{Abcg} 8$.
\end{abstract}

Key Words ATP-binding cassette transporter G5, ATP-binding cassette transporter G8, bile, cholesterol, soy protein isolate

ATP-binding cassette transporter G5 (ABCG5) and ATP-binding cassette transporter G8 (ABCG8) are mainly expressed in the liver and the intestine (1). It has been suggested that ABCG5 and ABCG8 have a function to excrete sterols from intestinal cells to the intestinal lumen and from the liver to the bile (1). Although functions of ABCG5 and ABCG8 on sterol excretion gradually become apparent, the contribution of ABCG5 and ABCG8 to cholesterol metabolism in the whole body is not fully understood and scarcely any information on regulation of ABCG5 and ABCG8 expression by dietary components has been obtained.

It has been reported that dietary soy protein isolate (SPI) and its undigested high molecular fraction (HMF) lower serum cholesterol concentration in experimental animals (2-4). One of the mechanisms of hypocholesterolemic effects of SPI and HMF is an increase in fecal bile acid excretion $(3,4)$. The increased excretion of bile acids can be caused by their binding with SPI and HMF $(3,4)$. Fecal excretion of neutral steroids originated from cholesterol was also increased by the feeding of SPI and HMF in rats fed a high-cholesterol diet (3-5). It has been thought that increased excretion of cholesterol and the metabolite coprostanol is caused by reduced availability of bile acids for the bile salt micelle in the intestinal lumen and therefore by reduced solu-

E-mail: iikeda@biochem.tohoku.ac.jp bility of cholesterol in the micelle (3, 4, 6). Although increased fecal excretion of cholesterol and coprostanol can be caused by increased expressions of ABCG5 and ABCG8 in the liver and the intestine, no information is available about whether SPI and HMF influence expressions and functions of ABCG5 and ABCG8 in the liver and the intestine. In the present study, we examined effects of SPI and HMF on cholesterol metabolism in relation to mRNA expressions of ABCG5 and ABCG8 in the liver and the intestine of rats.

\section{MATERIALS AND METHODS}

Materials. SPI (Fujipro-F) was kindly provided by Fuji Oil Co., Osaka Japan. HMF was prepared according to the method reported by Sugano et al. (3).

Methods. In Exps. 1 and 2, male Wistar rats (3 wk old, Kyudo, Saga, Japan) were housed individually in an air-conditioned room $\left(21-24^{\circ} \mathrm{C}\right.$, lights on 08:0020:00) and they were allowed free access to a commercial chow for $5 \mathrm{~d}$. Then, rats were divided into three groups. The composition of the experimental diets is shown in Table 1. Nitrogen content from each protein was adjusted to the same among the diets. Rats were fed one of the experimental diets for $3 \mathrm{wk}$ ad libitum in Exps. 1 and 2. In Exp. 1, feces were collected for $48 \mathrm{~h}$ at the end of the feeding period. In the morning of the last day of the feeding, rats were killed by withdrawing blood from the abdominal aorta without starvation 
Table 1. Dietary regimen.

\begin{tabular}{lrcr}
\hline & CAS & SPI & HMF \\
\hline & & (g/kg diet) & \\
Casein & 200 & - & 105.5 \\
SPI & - & 215.53 & - \\
HMF & - & - & 105.5 \\
$\alpha$-Cornstarch & 132 & 132 & 132 \\
Sucrose & 100 & 100 & 100 \\
Cellulose & 50 & 50 & 50 \\
Lard & 100 & 100 & 100 \\
Vitamin mix (AIN93) & 10 & 10 & 10 \\
Mineral mix (AIN93G) & 35 & 35 & 35 \\
L-Cystine & 3 & 3 & 3 \\
Choline bitartrate & 2.5 & 2.5 & 2.5 \\
TBHQ & 0.014 & 0.014 & 0.014 \\
Cornstarch & to 1,000 & to 1,000 & to 1,000 \\
\hline
\end{tabular}

under diethyl ether anesthesia. The liver and small intestine were excised. The intestine was divided into two equal parts, the jejunum and ileum, and the mucosa was scraped. In Exp. 2, the bile duct was cannulated in the morning of the last day of feeding under diethyl ether anesthesia and right after the cannulation, the bile was collected for $1 \mathrm{~h}$.

All animal studies were carried out under the guidelines for animal experiments of the Faculty of Agriculture, Graduate School of Kyushu University (Exp. 1) and of the Graduate School of Agricultural Science, Tohoku University (Exp. 2).

Lipid analyses. Serum total cholesterol concentration was determined by using an enzyme assay kit, Cholesterol C test Wako (Wako Pure Chemical Industries, Ltd., Osaka, Japan). Serum lipoproteins other than high density lipoproteins (HDL) were precipitated by using a solution containing 1\% dextran sulfate sodium salt and $7.11 \%$ magnesium chloride hexahydrate. After centrifugation and filtration, a clear supernatant containing HDL was obtained and then HDL-cholesterol was measured with Cholesterol $C$ test Wako. Total lipids in the liver and bile were extracted and purified by the procedure of Folch et al. (7). The concentration of hepatic cholesterol was determined chemically as described previously (8). After saponification of biliary lipids, unsaponifiable substances collected were derivatized to trimethylsilylether and were quantified by gaschromatography using SUPELCO SPB-1 column and $5 \alpha$-cholestane as an internal standard. Biliary phospholipid concentration was determined chemically (9). Total bile acid concentration in bile was determined enzymatically (10). After freeze-drying of feces, neutral and acidic steroids were extracted with hot ethanol and were subjected to analysis by gas-chromatography as described previously (11).

Analysis of mRNA expression. Total RNA was extracted from $1 \mathrm{~g}$ of liver and intestinal mucosa, using guanidium thiocyanate/cecium chloride ultracentrifugation as described by Sato et al. (12).

A TaqMan Universal PCR Master Mix (Applied
Table 2. Cholesterol concentrations in serum and liver.

\begin{tabular}{cccc}
\hline & CAS & SPI & HMF \\
\hline Serum (mg/dL) & & & \\
Total cholesterol & $104 \pm 8^{\mathrm{a}}$ & $77.7 \pm 6.3^{\mathrm{b}}$ & $85.7 \pm 3.9^{\mathrm{b}}$ \\
HDL-cholesterol & $68.6 \pm 9.3^{\mathrm{a}}$ & $44.6 \pm 4.7^{\mathrm{b}}$ & $52.2 \pm 5.1^{\mathrm{ab}}$ \\
Liver (mg/g Liver) & & & \\
Total cholesterol & $2.71 \pm 0.08^{\mathrm{a}}$ & $2.46 \pm 0.05^{\mathrm{b}}$ & $2.37 \pm 0.09^{\mathrm{b}}$ \\
\hline
\end{tabular}

Data are means \pm SE of 6 rats.

${ }^{\mathrm{ab}}$ Different letters show significant difference at $p<0.05$.

Biosystems, Tokyo, Japan); Assay-on-Demand, Gene Expression Products (Rn00587092_m1 for ABCG5, Rn00590367_m1 for ABCG8, Rn00710172_m1 for ATP-binding cassette transporter A1 (ABCA1), Rn00564065_m1 for cholesterol $7 \alpha$-hydroxylase (CYP7A1), Rn00581185_m1 for liver X receptor $\alpha$ (LXRa), Rn01443503_m1 for Niemann Pick C1 like 1 (NPC1L1), Rn00589173_m1 for small heterodimer partner (SHP), Rn01759149_m1 for liver receptor homologue 1 (LRH1), Rn00569117_m1 for fatty acid synthase (FAS), Hs99999901_s1 for 18S RNA, Applied Biosystems); and TaqMan MGB Gene Expression Kit for sterol regulatory element binding protein-1 (SREBP-1) were used for the quantitative real-time RT-PCR analysis of ABCG5, ABCG8, ABCA1, CYP7A1, LXR $\alpha$, NPC1L1, SHP, LRH1, FAS, 18S RNA, and SREBP-1 expression in the intestine and liver. The details of the TaqMan MGB Gene Expression Kits were as follows: SREBP-1 (forward primer, 5'-GCCCACAATGCCATTGAGA-3'; reverse primer, 5'-GCAAGACAGCAGATTTATTCAGCTT-3'; and TaqMan MGB probe, 5'-FAM-TATCAATGACAAGATTGTG-MGB-3'). The amplification was performed with a real-time PCR system (ABI Prism 7000 Sequence Detection System; Applied Biosystems). Results were quantified with a comparative method and were expressed as a relative value after normalization to the 18S RNA expression.

Statistical analysis. All data were expressed as means \pm SE. The Fisher PLSD test was used and $p$ values less than 0.05 were considered significant.

\section{RESULTS}

\section{Exp. 1}

There were no significant differences in food intake and body weight gain among the CAS, SPI and HMF groups (data not shown). Liver weight was $4.59 \pm 0.09 \mathrm{~g} / 100 \mathrm{~g}$ body weight in the CAS group, $4.93 \pm 0.16 \mathrm{~g} / 100 \mathrm{~g}$ body weight in the SPI group, and $4.44 \pm 0.10 \mathrm{~g} / 100 \mathrm{~g}$ body weight in the HMF group. A significant difference was observed between the SPI and HMF groups. Since hepatic hypertrophy in SPI feeding was not necessarily observed in previous studies (3-5), the cause is not exactly known at present.

The concentration of serum total cholesterol was significantly lower in the SPI and HMF groups than in the CAS group (Table 2). The concentration of HDL-cholesterol tended to be lower in the SPI and HMF groups 
Table 3. Excretions of fecal acidic and neutral steroids.

\begin{tabular}{|c|c|c|}
\hline & CAS & $\mathrm{HMF}$ \\
\hline Fecal weight $(\mathrm{g} / \mathrm{d})$ & $1.37 \pm 0.07^{\mathrm{a}} 1.69 \pm 0.05^{\mathrm{b}}$ & $1.61 \pm 0.02^{\mathrm{b}}$ \\
\hline Neutral steroids $^{1}(\mathrm{mg} / \mathrm{d})$ & l) $5.31 \pm 0.37^{\mathrm{a}} 5.23 \pm 0.14^{\mathrm{ab}}$ & $4.32 \pm 0.19^{b}$ \\
\hline Acidic steroids (mg/d) & $1.72 \pm 0.16^{\mathrm{a}} 3.44 \pm 0.34^{\mathrm{b}}$ & $5.13 \pm 0.56^{\mathrm{c}}$ \\
\hline
\end{tabular}

Table 4. mRNA expression levels in the liver.

\begin{tabular}{llll}
\hline & \multicolumn{1}{c}{ CAS } & \multicolumn{1}{c}{ SPI } & \multicolumn{1}{c}{ HMF } \\
\hline ABCA1 & $100 \pm 13$ & $101 \pm 16$ & $78.1 \pm 3.6$ \\
ABCG5 & $100 \pm 7^{\mathrm{a}}$ & $489 \pm 97^{\mathrm{b}}$ & $460 \pm 104^{\mathrm{b}}$ \\
ABCG8 & $100 \pm 21^{\mathrm{a}}$ & $239 \pm 38^{\mathrm{b}}$ & $254 \pm 43^{\mathrm{b}}$ \\
LXR $\alpha$ & $100 \pm 3$ & $89.7 \pm 12.0$ & $80.1 \pm 6.2$ \\
SREBP1 & $100 \pm 12$ & $76.4 \pm 11.5$ & $67.5 \pm 9.3$ \\
FAS & $100 \pm 12^{\mathrm{a}}$ & $49.3 \pm 13.8^{\mathrm{b}}$ & $35.8 \pm 5.5^{\mathrm{b}}$ \\
CYP7A1 & $100 \pm 20^{\mathrm{a}}$ & $168 \pm 47^{\mathrm{ab}}$ & $316 \pm 75^{\mathrm{b}}$ \\
SHP & $100 \pm 22^{\mathrm{a}}$ & $33.8 \pm 6.4^{\mathrm{b}}$ & $60.3 \pm 20.3^{\mathrm{b}}$ \\
LRH1 & $100 \pm 12$ & $90.4 \pm 14$ & $81.1 \pm 13.8$ \\
\hline
\end{tabular}

Data are means \pm SE of 6 rats.

Different letters show significant difference at $p<0.05$.

than in the CAS group and the difference between SPI and CAS groups was significant.

The concentration of hepatic cholesterol was significantly lower in the SPI and HMF groups than in the CAS group (Table 2). Fecal excretion of neutral steroids was almost the same between the CAS and SPI groups and it was significantly lower in the HMF group than in the CAS group (Table 3). Fecal excretion of acidic steroids was significantly higher in the SPI and HMF groups than in the CAS group and HMF was more effective at increasing acidic steroid excretion than SPI.

Expression of various genes related to lipid metabolism in the liver is shown in Table 4. Expressions of ABCG5 and ABCG8 mRNA were significantly higher in the SPI and HMF groups than in the CAS group. Expression of CYP7A1 was significantly higher in the HMF group and tended to be higher in the SPI group than in the CAS group. Expression of FAS and SHP was significantly lower in the SPI and HMF groups than in the CAS group. There were no significant differences in expression of ABCA1, LXR $\alpha$, SREBP-1, or LRH1 among the three groups. We also measured mRNA expression of ABCA1, ABCG5, ABCG8, and NPC1L1 in the proximal and distal intestines. There were no significant differences in any of the genes among the three groups (data not shown).

Exp. 2

There were no significant differences in food intake or body weight gain among the CAS, SPI and HMF groups (data not shown). Bile flow rates were almost the same among the three groups (Table 5). The amounts of cholesterol and phospholipids were significantly higher in
Table 5. Biliary excretions of cholesterol, bile acids and phospholipids.

\begin{tabular}{lccc}
\hline & CAS & SPI & HMF \\
\hline Bile flow $(\mathrm{mL} / \mathrm{h})$ & $0.84 \pm 0.04$ & $0.83 \pm 0.02$ & $0.86 \pm 0.07$ \\
Cholesterol $(\mu \mathrm{g} / \mathrm{h})$ & $115 \pm 9^{\mathrm{a}}$ & $154 \pm 6^{\mathrm{b}}$ & $152 \pm 12^{\mathrm{b}}$ \\
Bile acids $(\mathrm{nmol} / \mathrm{h})$ & $27.0 \pm 1.7$ & $27.4 \pm 2.0$ & $32.2 \pm 2.7$ \\
Phospholipids $(\mu \mathrm{mol} / \mathrm{h})$ & $3.66 \pm 0.38^{\mathrm{a}}$ & $5.06 \pm 0.24^{\mathrm{b}}$ & $4.91 \pm 0.31^{\mathrm{b}}$
\end{tabular}

Data are means \pm SE of 6 or 7 rats.

Different letters show significant difference at $p<0.05$.

the SPI and HMF groups than in the CAS group. No significant difference was observed in the amount of bile acids among the three groups.

\section{DISCUSSION}

Yu et al. showed that in ABCG5- and ABCG8-deficient mice, secretion of biliary cholesterol was extremely low compared with wild-type mice (13). The observation means that ABCG5 and ABCG8 expressed in the liver have a crucial role in the excretion of cholesterol from the liver to the bile. The present study showed for the first time that dietary SPI and HMF, compared with CAS, significantly increased mRNA expressions of ABCG5 and ABCG8 in the liver, but not in the intestine in Exp. 1 (Table 4). The feeding of SPI and HMF stimulated biliary excretion of cholesterol in Exp. 2 (Table 5). Our observations strongly suggest a possibility that stimulated excretion of biliary cholesterol by the feeding of SPI and HMF is caused by increased expression of hepatic ABCG5 and ABCG8 in SPI and HMF groups.

Biliary cholesterol secretion was 39 and $37 \mu \mathrm{g} / \mathrm{h}$ higher in the SPI and HMF groups, respectively, than in the CAS group (Table 5). This means that around $900 \mu \mathrm{g} / \mathrm{d}$ higher cholesterol as excreted to the bile in the former two groups. This can be a cause of the reduction of hepatic cholesterol in the SPI and HMF groups. If intestinal absorption of cholesterol is estimated to be $50 \%, 450 \mu \mathrm{g}$ higher cholesterol can be excreted to the feces in the SPI and HMF groups compared with the CAS group. Since fecal excretion of neutral steroids was around $5 \mathrm{mg} / \mathrm{d}$ (Table 3), a 10\% increase of fecal neutral steroid excretion should be obtained in the SPI and HMF groups, compared with the CAS group. Nagata et al. observed that dietary SPI, in comparison with CAS, increased fecal neutral steroid excretion in rats fed a cholesterol-free diet (5). They also observed that when radiolabeled cholesterol was intravenously administered in rats fed a cholesterol-free diet containing SPI or CAS, fecal excretion of the radioactivity as both neutral and acidic steroids was increased in the SPI feeding (14). The results suggest that biliary and fecal excretion of endogenous cholesterol is increased in the feeding of SPI. However, no increased excretion of fecal neutral steroid was observed in the SPI or HMF group in the present study (Table 3). Although the cause cannot be explained at present, our results suggest that SPI potentially accelerates biliary cholesterol excretion. However, 
the amount does not necessarily make a large contribution to fecal cholesterol excretion, at least under these experimental conditions. Therefore, it is not clear whether increased excretion of biliary cholesterol in the feeding of SPI and HMF has an important implication for the overall cholesterol pool in the body. There is a possibility that an increase in biliary cholesterol secretion reduces hepatic cholesterol and induces incorporation of LDL-cholesterol from the bloodstream to the liver and therefore, contributes to the reduction of serum cholesterol concentration.

It has been reported that ABCG 5 and ABCG8 are target genes of $\operatorname{LXR} \alpha$, a nuclear receptor (15). The binding of oxygenated sterols to $\operatorname{LXR} \alpha$ is expected to activate mRNA expressions of various enzymes and transporters, such as SREBP-1, FAS, CYP7A1 and ABCA1 (16). Therefore, we measured mRNA expressions of these proteins in the liver. Although CYP7A1 mRNA expression tended to be higher in the SPI and HMF groups, FAS mRNA expression was significantly suppressed in the SPI and HMF groups (Table 4). ABCA1 mRNA expression was not changed in the feeding of SPI or HMF. It has been reported that gene expression of SREBP-1 and FAS was lower, but that of CYP7A1 was higher in the feeding of soy protein compared with that of casein $(17,18)$. These observations suggest that $\mathrm{LXR} \alpha$ is not necessarily activated in the feeding of SPI and HMF and therefore, increased expression of hepatic ABCG5 and ABCG8 in SPI and HMF groups is not caused by the activation of $\operatorname{LXR} \alpha$.

In the present study, we observed the reduction of mRNA expression of liver SHP in the feeding of SPI and HMF (Table 4). It has been known that mRNA expression of SHP is enhanced in response to bile acids bound to the farnesoid $X$ receptor (FXR), which binds to the promoter of Shp (19). Since fecal excretion of acidic steroids was increased in the feeding of SPI and HMF, it is thought that the amount of bile acids returned to the liver through the enterohepatic circulation is lower in the feeding of SPI and HMF than in the CAS feeding. Therefore, the reduction of the gene expression of SHP in the feeding of SPI and HMF can be caused by an insufficiency of hepatic bile acids. SHP interacts with LRH1 and down-regulates CYP7A1 transcription (19). The reduction of SHP expression increases LRH1 not interacted with SHP, which can induce an increase of mRNA expression of CYP7A1. This can be a mechanism in which bile acid synthesis is induced in the case of bile acid insufficiency. In the present study, mRNA expression of CYP7A1 tended to increase in the feeding of SPI and significantly increased in the feeding of HMF (Table 4). Increased expression of CYP7A1 mRNA in the feeding of SPI was also reported by others (17). A recent study revealed that $\mathrm{LRH} 1$ activates the intergenic promoter of human ABCG5/ABCG8 (20). It has been reported that the LRH1 binding site is conserved in the rat $A b c g 5 / A b c g 8$ intergenic region (21). These observations suggest that an increase of LRH1 not interacted with SHP is responsible for the observed increase of ABCG5 and ABCG8 mRNA expression. In contrast to the liver, we did not observe any differences in mRNA expressions of ABCG5 or ABCG8 in the intestine. Further investigation is necessary to determine why the feeding of SPI and HMF did not influence their expressions in the intestine.

If increased expression of ABCG5 and ABCG8 is induced by increased fecal excretion of bile acids, bile acid sequestrants can have the same influence on expressions of SHP, ABCG5 and ABCG8. Gupta et al. reported that feeding of cholestyramine in rats resulted in a marked repression of hepatic SHP mRNA expression (22). In contrast, Shibata et al. did not observe a reduction of hepatic SHP mRNA in the feeding of cholestyramine in rats, although CYP7A1 expression was enhanced (23). Since no information is available on effects of bile acid sequestrants on the expression of hepatic ABCG5 and ABCG8, more studies will be necessary on this point.

\section{REFERENCES}

1) Lu K, Lee MH, Patel SB. 2001. Dietary cholesterol absorption; more than just bile. Trends Endocrinol Metab 12: $314-320$.

2) Torres N, Torre-Villalvazo I, Tovar AR. 2006. Regulation of lipid metabolism by soy protein and its implication in diseases mediated by lipid disorders. J Nutr Biochem 17: 365-373.

3) Sugano M, Yamada Y, Yoshida K, Hashimoto Y, Matsuo T, Kimoto M. 1988. The hypocholesterolemic action of the undigested fraction of soybean protein in rats. Atherosclerosis 72: 115-122.

4) Sugano M, Goto S, Yamada Y, Yoshida K, Hashimoto Y, Matsuo T, Kimoto M. 1990. Cholesterol-lowering activity of various undigested fractions of soybean protein in rats. J Nutr 120: 977-985.

5) Nagata Y, Tanaka K, Sugano M. 1981. Further studies on the hypocholesterolemic effect of soya-bean protein in rats. Br J Nutr 45: 233-241.

6) Choi S-K, Adachi M, Utsumi S. 2002. Identification of the bile acid-binding region in the soy glycinin $\mathrm{A} 1 \mathrm{aB} 1 \mathrm{~b}$ subunit. Biosci Biotechnol Biochem 66: 2395-2401.

7) Folch J, Lees M, Sloane Stanley GH. 1957. A simple method for the isolation and purification of total lipids from animal tissue. J Biol Chem 226: 497-506.

8) Sperry WM, Webb M. 1950. A revision of the Schoenheimer-Sperry method for cholesterol determination. J Biol Chem 187: 97-106.

9) Rouser G, Siakotos AN, Fleischer S. 1966. Quantitative analysis of phospholipids by thin-layer chromatography and phosphorus analysis of spots. Lipids 1: 85-86.

10) Eaton DL, Klaassen CD. 1976. Effects of acute administration of taurocholic and taurochenodeoxycholic acids on biliary lipid excretion in the rat. Proc Soc Exp Biol Med 151: 198-202.

11) Ikeda I, Wakamatsu K, Inayoshi A, Imaizumi K, Sugano M, Yazawa K. 1994. $\alpha$-Linolenic, eicosapentaenoic and docosahexaenoic acids affect lipid metabolism differently in rats. J Nutr 124: 1898-1906.

12) Sato M, Imaizumi K, Mori H, Sugano M. 1992. Regulation of intestinal apo A-IV mRNA abundance in rat pups during fasting and refeeding. Biosci Biotechnol Biochem 1165: 93-101.

13) Yu L, Hammer RE, Li-Hawkins J, von Bergmann K, Lut- 
johann D, Cohen JC, Hobbs HH. 2002. Disruption of Abcg 5 and Abcg 8 in mice reveals their crucial role in biliary cholesterol secretion. PNAS 99: 16237-16242.

14) Nagata Y, Ishiwaki N, Sugano M. 1982. Studies of the mechanism of antihypercholesterolemic action of soy protein and soy protein-type amino acid mixtures in relation to the casein counterparts in rats. J Nutr 112: 1614-1625.

15) Repa JJ, Berge KE, Pomajzl C, Richardson JA, Hobbs H, Mangelsdorf DJ. 2002. Regulation of ATP-binding cassette sterol transporters ABCG5 and ABCG8 by the liver $\mathrm{X}$ receptors $\alpha$ and $\beta$. J Biol Chem 277: 18793-18800.

16) Bocher V, Millatt LJ, Fruchart J-C, Staels B. 2003. Liver $\mathrm{X}$ receptors: new players in atherogenesis? Curr Opin Lipidol 14: 137-143.

17) Ascencio C, Torres N, Isoard-Acosta F, Gomez-Perez FJ, Hernandez-Pando R, Tovar AR. 2004. Soy protein affects serum insulin and hepatic SREBP-1 mRNA and reduces fatty liver in rats. J Nutr 134: 522-529.

18) Tovar AR, Murguia F, Cruz C, Hernandez-Pando R, Aguilar-Salinas CA, Pedraza-Chaverri J, Correa-Rotter R, Torres N. 2002. A soy protein diet alters hepatic lipid metabolism gene expression and reduces serum lipids and renal fibrogenic cytokines in rats with chronic nephritic syndrome. J Nutr 132: 2562-2569.

19) Davis RA, Miyake JH, Hui TY, Spann NJ. 2002. Regulation of cholesterol- $7 \alpha$-hydroxylase: BAREly missing a SHP. J Lipid Res 43: 533-543.

20) Freeman LA, Kennedy A, Wu J, Bark S, Remaley AT, Santamarina-Fojo S, Brewer Jr B. 2004. The orphan nuclear receptor LRH-1 activates the ABCG5/ABCG8 intergenic promoter. J Lipid Res 45: 1197-1206.

21) Reley AT, Bark S, Walts AD, Freeman L, Shulenin S, Annilo T, Elgin E, Rhodes HE, Joyce C, Dean M, Santamarina-Fojo S, Brewer Jr HB. 2002. Comparative genome analysis of potential regulatory elements in the ABCG5-ABCG8 gene cluster. Biochem Biophys Res Commun 295: 276-282.

22) Gupta S, Pandak, WM, Hylemon PB. 2002. LXR $\alpha$ is the dominant regulator of CYP7A1 transcription. Biochem Biophys Res Commun 293: 338-343.

23) Shibata S, Kayakawa K, Egashira Y, Sanada H. 2007. Role of nuclear receptors in the up-regulation of hepatic cholesterol $7 \alpha$-hydroxylase by cholestyramine in rats. Life Sci 80: 546-553. 